\title{
Biodegradation
}

\section{of 2-chloro-4-nitrophenol via a hydroxyquinol pathway by a Gram-negative bacterium, Cupriavidus sp. strain CNP-8}

\author{
Jun Min ${ }^{1}$, Jinpei Wang ${ }^{2}$, Weiwei Chen ${ }^{1}$ and Xiaoke $\mathrm{Hu}^{1^{*}}$ (1)
}

\begin{abstract}
Cupriavidus sp. strain CNP-8 isolated from a pesticide-contaminated soil was able to utilize 2-chloro-4-nitrophenol (2C4NP) as a sole source of carbon, nitrogen and energy, together with the release of nitrite and chloride ions. It could degrade 2C4NP at temperatures from 20 to $40{ }^{\circ} \mathrm{C}$ and at $\mathrm{pH}$ values from 5 to 10 , and degrade 2C4NP as high as $1.6 \mathrm{mM}$. Kinetics assay showed that biodegradation of 2C4NP followed Haldane substrate inhibition model, with the maximum specific growth rate $\left(\mu_{\max }\right)$ of $0.148 / \mathrm{h}$, half saturation constant $\left(K_{\mathrm{s}}\right)$ of $0.022 \mathrm{mM}$ and substrate inhibition constant $\left(K_{\mathrm{i}}\right)$ of $0.72 \mathrm{mM}$. Strain CNP-8 was proposed to degrade 2C4NP with hydroxyquinol (1,2,4-benzenetriol, BT) as the ring-cleavage substrate. The 2C4NP catabolic pathway in strain CNP-8 is significant from those reported in other Gram-negative 2C4NP utilizers. Enzymatic assay indicated that the monooxygenase initiating 2C4NP catabolism had different substrates specificity compared with previously reported 2C4NP monooxygenations. Capillary assays showed that strain CNP-8 exhibited metabolism-dependent chemotactic response toward 2C4NP at the optimum concentration of $0.5 \mathrm{mM}$ with a maximum chemotaxis index of 37.5. Furthermore, microcosm studies demonstrated that strain CNP-8, especially the pre-induced cells, could remove 2C4NP rapidly from the 2C4NP-contaminated soil. Considering its adaptability to $\mathrm{pH}$ and temperature fluctuations and great degradation efficiency against 2C4NP, strain CNP-8 could be a promising candidate for the bioremediation of 2C4NP-contaminated sites.
\end{abstract}

Keywords: 2-Chloro-4-nitrophenol, Hydroxyquinol pathway, Kinetics, Chemotaxis, Cupriavidus sp. strain CNP-8

\section{Introduction}

Chloronitrophenols (CNPs) are typical representatives of chlorinated nitroaromatics, which are widely utilized in synthesizing pesticides, fungicides, drugs, dyes, among others (Arora et al. 2012a, b). The natural formation of CNPs is extremely rare, and most of these xenobiotics in the environment are mainly coming from their manufacture and use, and the chemical or biological degradation of their derivatives. As the most common isomer of CNPs, 2-chloro-4-nitrophenol (2C4NP) is used for

\footnotetext{
*Correspondence: xkhu@yic.ac.cn

${ }^{1}$ Key Laboratory of Coastal Biology and Bioresource Utilization, Yantai Institute of Coastal Zone Research, Chinese Academy of Sciences, Yantai 264003, China

Full list of author information is available at the end of the article
}

production of herbicide dicapthon and fungicide nitrofungin (Min et al. 2014). Due to its water solubility and high mobility, 2C4NP has caused serious contamination to agricultural soils and water resources, and has caused severe health effects to humans and animals (Arora et al. 2014a). Therefore, removal of 2C4NP from the environment has recently aroused wide concern.

In the past decade, several physico-chemical methods have been reported on the degradation of 2C4NP (Priya and Madras 2006; Verma et al. 2015); however, these methods are cost-consuming and do not yield complete mineralization of 2C4NP. Bioremediation process, which is more environmental-friendly and cost-effective in comparison with physico-chemical methods, has turned out to be a promising strategy for degradation of various 
nitrophenol pollutants (Chi et al. 2013; Wang et al. 2014; Min et al. 2017a; Xu and Zhou 2017). Moreover, microbial-based processes can be also effectively integrated with the activated sludge system which was already used in the conventional effluent treatment plants.

Although 2C4NP is released into the environment for a relatively short period, several microorganisms have evolved their ability to degrade this xenobiotic (Ghosh et al. 2010; Arora and Jain 2011; Pandey et al. 2011; Arora and Jain 2012; Tiwari et al. 2017). The Gram-negative Burkholderia sp. strain SJ98 degraded 2C4NP with chlorohydroquinone (CHQ) as the ring-cleavage compound (Min et al. 2014), whereas the Gram-positive Rhodococcus imtechensis RKJ 300 degraded 2C4NP with hydroxyquinol (1,2,4-benzenetriol, BT) as the ring-cleavage compound (Min et al. 2016). Burkholderia sp. RKJ800, another Gram-negative 2C4NP-utilizer, was reported to initiate 2C4NP degradation with formation of $\mathrm{CHQ}$, which was then dechlorinated to hydroquinone (HQ) (Arora and Jain 2012). Due to its high toxicity, 2C4NP with concentration more than $0.5 \mathrm{mM}$ was reported to inhibit the growth of previously reported 2C4NP-utilizers (Arora and Jain 2012; Tiwari et al. 2017). Furthermore, most 2C4NP-utilizers were reported to degrade 2C4NP at neutral $\mathrm{pH}$. Industrial wastewaters, especially the pesticide production wastewaters, may contain high concentration of $2 \mathrm{C} 4 \mathrm{NP}$ and the $\mathrm{pH}$ often varies widely. Thus, the search for new microorganisms that can adapt to a wide $\mathrm{pH}$ range and degrade $2 \mathrm{C} 4 \mathrm{NP}$ at high concentration is still of great scientific and industrial significance.

In this study, Cupriavidus sp. strain CNP-8 has ability to adapt a wide range of $\mathrm{pH}$ and temperature and utilize $2 \mathrm{C} 4 \mathrm{NP}$ up to a concentration of $1.6 \mathrm{mM}$, which is apparently higher than the maximum concentration degraded by previous $2 \mathrm{C} 4 \mathrm{NP}$-utilizers. Strain CNP-8 was proposed to degrade $2 \mathrm{C} 4 \mathrm{NP}$ via the $\mathrm{BT}$ pathway, which was reported in a Gram-negative 2C4NP-degrading bacterium for the first time. The kinetics of $2 \mathrm{C} 4 \mathrm{NP}$ degradation and the chemotaxis of $2 \mathrm{C} 4 \mathrm{NP}$ by this strain was also investigated. Microcosm studies demonstrated that strain CNP-8 could be an efficient candidate for bioremediation application.

\section{Materials and methods}

\section{Bacterial strain, media and chemicals}

Strain CNP-8 was recently isolated from the pesticidecontaminated soil collected from Yantai, Shandong, China (Min et al. 2017b). It has been deposited in the China Center for Type Culture Collection (Wuhan) with accession number CCTCC M 2017546. Compounds 2C4NP, 2-chloro-5-nitrophenol (2C5NP), 4-chloro-2-nitrophenol (4C2NP), 5-chloro-2-nitrophenol (5C2NP),
BT, CHQ, para-nitrophenol (PNP) and meta-nitrophenol (MNP) were purchased from Sigma Chemical Co.

\section{Biodegradation experiments}

Biodegradation experiments were carried out in $250 \mathrm{~mL}$ Erlenmeyer flasks containing $100 \mathrm{~mL} \mathrm{MSM}$ with 2C4NP as a sole source of carbon, nitrogen and energy. The 2C4NP degradation ability of strain CNP-8 was determined by monitoring the bacterial growth $\left(\mathrm{OD}_{600}\right)$ and $2 \mathrm{C} 4 \mathrm{NP}$ consumption. To investigate the effect of $\mathrm{pH}$ and temperature on 2C4NP degradation, biodegradation experiments were performed at different $\mathrm{pH}(4-10)$ and temperatures $\left(20-40{ }^{\circ} \mathrm{C}\right)$. Glucose $(0.2,0.5$ or $5 \mathrm{~g} / \mathrm{L})$ was added into the MSM to study the effect of supplemented carbon source on 2C4NP degradation. For these biodegradation experiments, strain CNP-8 was initially grown in MSM + lysogeny broth (LB) $(4: 1, v / v)$ containing $0.3 \mathrm{mM}$ of $2 \mathrm{C} 4 \mathrm{NP}$. After overnight growth, cells were harvested, washed twice and resuspended in fresh MSM. The cells suspension was added in the test medium at initial $\mathrm{OD}_{600}$ of 0.05 , and the flasks were then shaken at $180 \mathrm{rpm}$. All above experiments were performed in triplicate.

\section{C4NP degradation kinetics}

To estimate the kinetics parameters of 2C4NP degradation, the effect of initial $2 \mathrm{C} 4 \mathrm{NP}$ concentration (0.05-2 mM) on growth of strain CNP-8 was investigated. Cell growth kinetics was modeled by the following equation as described (Wang et al. 2010):

$$
\mu=\frac{\ln \left(X / X_{0}\right)}{t-t_{0}}
$$

where $X$ represents the biomass $(\mathrm{mg} / \mathrm{L}), \mu$ represents the specific growth rate $\left(\mathrm{h}^{-1}\right)$ and $\mathrm{t}$ represents the time.

Haldane's model, widely used to describe the growth kinetics of toxic compounds (Shen et al. 2009; Banerjee and Ghoshal 2011), was selected to investigate the growth kinetics of 2C4NP. The Haldane's inhibitory growth kinetics equation is as follows:

$$
\mu=\frac{\mu_{\max } S}{K_{s}+S+\left(S^{2} / K_{i}\right)}
$$

where $S$ represents substrate concentration $(\mathrm{mg} / \mathrm{L}), \mu_{\max }$ represents the maximum specific growth rate $\left(\mathrm{h}^{-1}\right), K_{\mathrm{s}}$ represents half saturation constant $(\mathrm{mg} / \mathrm{L}), K_{\mathrm{i}}$ represents inhibition constant ( $\mathrm{mg} / \mathrm{L})$.

The biomass yield coefficient (mg dry cell/mg 2C4NP) was calculated by the following equation:

$$
Y=\frac{X_{\max }-X_{0}}{S_{0}-S_{a}}
$$


where $X_{\max }$ represents the maximum biomass concentration $(\mathrm{mg} / \mathrm{L}) ; X_{0}$ represents initial biomass concentration; $S_{0}$ represents initial substrate concentration $(\mathrm{mg} / \mathrm{L}) ; S_{\mathrm{a}}$ represents substrate concentration when biomass concentration reached maximum. The dry weight of biomass was converted from the $\mathrm{OD}_{600}$ value using a standard curve (dry weight $(\mathrm{mg} / \mathrm{L})=564.7 \times \mathrm{OD}_{600}-2.75$, $\mathrm{R}^{2}=0.986$ ).

\section{Analytical methods}

High performance liquid chromatography (HPLC) performed on an Agilent 1200 system was carried out to determine the concentration of 2C4NP and its metabolites with the mobile phase as described (Min et al. 2014). 2C4NP and the metabolites were quantified at $280 \mathrm{~nm}$. For gas chromatography-mass spectrometry (GC-MS) analysis, the intermediates were acetylated as described (Perry and Zylstra 2007). The condition of GC-MS analysis was the same as described (Liu et al. 2010). The acetylated derivatives of the intermediates were identified based on comparisons of the mass spectra and GC retention times with those of the acetylated standards. Nitrite was assayed as described (Lessner et al. 2002). Chloride ion was detected with an ion-selective combination chloride electrode (Model 96-17, Orion, Boston).

\section{Biotransformation and enzymatic assay of the crude cell extract}

Strain CNP-8 was grown in LB or MSM + LB (4:1, $v / v)$ containing $0.3 \mathrm{mM} 2 \mathrm{C} 4 \mathrm{NP}$, the cells were harvested at the exponential growth phase, washed twice and resuspended in $20 \mathrm{mM}$ phosphate buffer $\left(\mathrm{pH}\right.$ 7.2) to $\mathrm{OD}_{600}$ of 2.0. Biotransformation was performed with addition of $0.4 \mathrm{mM}$ of substrates. The crude cell extract was prepared by ultrasonication followed by a centrifugation at $4{ }^{\circ} \mathrm{C}$ for $40 \mathrm{~min}$ at $20,000 \times g$. The catalytic activity of the cell extract against 2C4NP, PNP and BT was determined spectrophotometrically. For 2C4NP and PNP transformation, the reaction mixture contained $20 \mathrm{mM}$ phosphate buffer $(\mathrm{pH} 7.2)$, crude cell extracts, substrate (2C4NP or PNP, $20 \mu \mathrm{M})$, NADPH $(100 \mu \mathrm{M})$, FAD $(10 \mu \mathrm{M})$ and $\mathrm{MgSO}_{4}(1 \mathrm{mM})$ in a final volume of $500 \mu \mathrm{l}$. The reaction mixture for $\mathrm{BT}$ transformation contained $20 \mathrm{mM}$ phosphate buffer, crude cell extracts and $100 \mu \mathrm{M}$ of BT. In these enzymatic assays, the reference cuvette contained all components except the substrate, and activity assay was initiated with the addition of substrate.

\section{Chemotaxis of strain CNP-8}

The chemotaxis of strain CNP-8 toward (chloro)nitrophenols was investigated as described (Arora and Bae 2014), with minor modification. For drop plate assay, strains SJ98 was grown in MSM+LB $(v / v=4: 1)$ to exponential phase, and then induced by $0.3 \mathrm{mM}$ of target substrate (2C4NP, 2C5NP, PNP or MNP) for $8 \mathrm{~h}$. The cells were harvested by centrifugation at $4000 \times g$ for $10 \mathrm{~min}$, washed twice with MSM, resuspended in the drop plate assay medium (MSM with $0.3 \%$ bacto agar) and transferred into petri-plate. Crystals of (chloro)nitrophenols were placed at the center of the plate and then incubated at $30{ }^{\circ} \mathrm{C}$ for $8-12 \mathrm{~h}$. For quantitative capillary assay, the solutions of each substrate at different concentrations (from 0.05 to $0.7 \mathrm{mM}$ in chemotaxis buffer which contained $100 \mathrm{mM}$ potassium phosphate ( $\mathrm{pH} 7.0)$ and $20 \mu \mathrm{M}$ EDTA) were filled into $10 \mu \mathrm{l}$ glass capillaries. The capillaries were inserted into the cell suspension of strain CNP-8 $\left(\sim 10^{11}\right.$ cells $\left./ \mathrm{mL}\right)$ on a glass slide. The capillary tube containing chemotaxis buffer $[100 \mathrm{mM}$ potassium phosphate ( $\mathrm{pH} 7.0)$ with $20 \mu \mathrm{M}$ EDTA] was used as control. After $30 \mathrm{~min}$ incubation at $30{ }^{\circ} \mathrm{C}$, the solutions in the capillaries were diluted serially and spread onto LB plates. The total number of colony forming units (CFUs) was determined after $48 \mathrm{~h}$ incubation at $30^{\circ} \mathrm{C}$. The chemotaxis index (CFUs produced from capillary containing the target substrate/CFUs from a control capillary) was used to quantify the chemotactic response.

\section{Soil microcosm study}

The soil was collected from an agricultural loam soil on the campus of the Yantai College of China Agricultural University, without pesticide contamination history. The total organic carbon, total organic nitrogen and moisture contents of the soil were $0.86,0.074$, and $10.64 \%$, respectively, and the $\mathrm{pH}$ was 7.38 . Soil in the sterile groups was sterilized three times by autoclaving at $121^{\circ} \mathrm{C}$ for $30 \mathrm{~min}$. Microcosms were set up in 250-mL glass bottles containing $110.6 \mathrm{~g}$ wet weight of soil [ $100 \mathrm{~g}$ dry weight $(\mathrm{dw})$ ]. Six different treatments were set up in triplicate: (T1) native soil with 2C4NP; (T2) sterilized soil with 2C4NP; (T3) native soil with 2C4NP and un-induced strain CNP-8; (T4) native soil with 2C4NP and 2C4NP-induced strain CNP-8; (T5) sterilized soil with 2C4NP and un-induced strain CNP-8; (T6) sterilized soil with 2C4NP and 2C4NP-induced strain CNP-8. 2C4NP with final concentrations of $100 \mu \mathrm{g} / \mathrm{g} \mathrm{dw}$ was added to the soil and mixed thoroughly. For bioaugmentation, strain CNP-8 was grown in LB or MSM+LB $(4: 1, v / v)$ containing $0.3 \mathrm{mM}$ of 2 C4NP. Both the un-induced and induced cells were harvested at the exponential phase, cells were washed twice and resuspended in $0.85 \%$ sterile saline before being inoculating at $\sim 1 \times 10^{9} \mathrm{CFUs} / \mathrm{g} \mathrm{dw}$. An equivalent volume of sterile saline was added to microcosms not containing strain CNP-8. The bottles were thoroughly mixed and kept at $30^{\circ} \mathrm{C}$. Then, $0.5 \mathrm{~g}$ of soil samples was taken periodically. The method described previously (Niu et al. 2009) was followed to extract 2C4NP from the soil 
samples, and 2C4NP was quantified by HPLC analysis as described above.

\section{Results \\ 2C4NP degradation and bacterial growth}

Strain CNP-8, a member of the genus Cupriavidus (Genbank number of 16S rRNA sequence: KY643479) was isolated from pesticide-contaminated soil in Yantai, China. It has been deposited in the China Center for Type Culture Collection (Wuhan) with accession number CCTCC M 2017546. It completely degraded $0.3 \mathrm{mM}$ of $2 \mathrm{C} 4 \mathrm{NP}$ after $20 \mathrm{~h}$ incubation with release of nitrite and chloride ions. Meanwhile, the $\mathrm{OD}_{600}$ increased from initial 0.052 to final 0.135 (Fig. 1). This revealed that strain CNP-8 has the ability to utilize 2C4NP as sole source of carbon, nitrogen and energy, and the cell growth was closely correlated with the amount of 2C4NP utilized. Particularly, the amount of nitrite was found to be higher than that of chloride ion at each time-point when $\left(\mathrm{NH}_{4}\right)_{2} \mathrm{SO}_{4}(1 \mathrm{~g} / \mathrm{L})$ was added into the MSM (data not shown), implying that the release of nitro group occurred prior to the removal of chloride. Moreover, the growth of strain CNP-8 on 2C4NP had a lag phase of about $4 \mathrm{~h}$, indicating that strain CNP-8 had an induction period during 2C4NP degradation. In addition to 2C4NP, strain CNP-8 was also able to utilize 2C5NP and MNP; but it unable to degrade PNP, 4C2NP and 5C2NP (Additional file 1: Table S1).

\section{Effect of temperature, $\mathrm{pH}$ and additional glucose concentration on 2C4NP biodegradation}

Biodegradation of $2 \mathrm{C} 4 \mathrm{NP}$ by strain CNP-8 at different temperatures $\left(20-40{ }^{\circ} \mathrm{C}\right)$ was examined when the $\mathrm{pH}$ of the MSM was fixed at 7. Strain CNP-8 had the highest efficiency of $2 \mathrm{C} 4 \mathrm{NP}$ degradation at $30{ }^{\circ} \mathrm{C}$, with rate of approximate $14.3 \mu \mathrm{M} / \mathrm{h}$. The degradation rate declined by $32 \%$ when the culture temperature was increased to

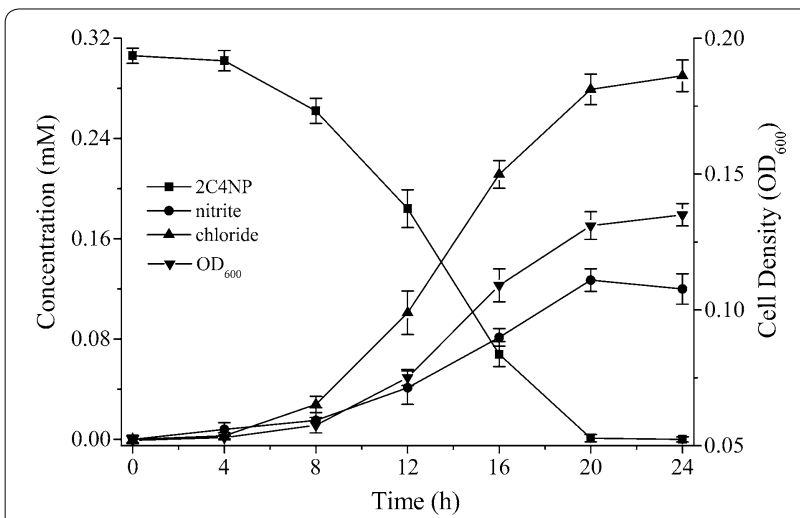

Fig. 1 Degradation of 2C4NP by Cupriavidus sp. strain CNP-8, together with the accumulation of nitrite, chloride and the bacterial biomass (indicated by $\mathrm{OD}_{600}$ )
$35{ }^{\circ} \mathrm{C}$, and declined by $25 \%$ when the temperature was reduced to $25{ }^{\circ} \mathrm{C}$ (Table 1 ). The 2C4NP degradation rate further reduced with the temperature increasing or decreasing; nevertheless, strain CNP-8 at a high temperature of $40{ }^{\circ} \mathrm{C}$ and a low temperature of $20^{\circ} \mathrm{C}$ was still able to degrade $0.3 \mathrm{mM}$ of $2 \mathrm{C} 4 \mathrm{NP}$ completely within 62 and $57 \mathrm{~h}$, respectively.

To investigate the effect of $\mathrm{pH}$ on 2C4NP degradation, strain CNP-8 was inoculated into MSM with $\mathrm{pH}$ ranging from 4 to 10 . The cultural temperature was fixed at $30{ }^{\circ} \mathrm{C}$. Strain CNP-8 exhibited the highest degradation rate against $2 \mathrm{C} 4 \mathrm{NP}$ at $\mathrm{pH}$ 7. The degradation rates at $\mathrm{pH} 6$ and 8 were slightly lower than that at $\mathrm{pH} 7$. Although the degradation rates at $\mathrm{pH} 5,9$ and 10 dropped significantly, strain CNP-8 was still able to degrade 2C4NP completely (Table 1). Neither 2C4NP degradation nor cell growth was detected at $\mathrm{pH} 4$. The special $\mathrm{pH}$ adaptability indicated that strain CNP-8 can be used under different conditions without adjusting the $\mathrm{pH}$ values.

Glucose with different concentrations $(0.2,0.5$ or $5 \mathrm{~g} / \mathrm{L}$ ) was added to MSM with $0.3 \mathrm{mM}$ of $2 \mathrm{C} 4 \mathrm{NP}$ to investigate the effect of supplemental carbon source on 2C4NP degradation. Glucose with concentrations of 0.2 and $0.5 \mathrm{~g} / \mathrm{L}$ can accelerate 2C4NP degradation, and the degradation rate of $0.2 \mathrm{~g} / \mathrm{L}$ addition was higher than that of $0.5 \mathrm{~g} / \mathrm{L}$ addition (Table 1 ). Although the biomass increased remarkably when the concentration of glucose was increased up to $5 \mathrm{~g} / \mathrm{L}$, the 2C4NP degradation rate declined significantly. This indicated that addition of easily degraded substrate is beneficial for 2C4NP biodegradation, but it is in a dose dependent manner.

\section{Kinetic studies of 2C4NP degradation by strain CNP-8}

Degradation of 2C4NP at different concentrations (0.05-2 mM) was carried out to determine the kinetic parameters of 2C4NP biodegradation. As shown in Fig. 2, strain CNP-8 degraded 2C4NP completely when the substrate concentration was less than $1.6 \mathrm{mM}$. Both substrate degradation and cell growth were gradually delayed with increase of 2C4NP concentration. Neither substrate degradation nor cell growth was observed when the concentration of $2 \mathrm{C} 4 \mathrm{NP}$ was increased up to $2 \mathrm{mM}$, suggesting that $2 \mathrm{C} 4 \mathrm{NP}$ concentrations in excess of $2 \mathrm{mM}$ would completely inhibit the growth of strain CNP-8.

Haldane's model, widely used to investigate microbial growth kinetics on aromatic compounds (Shen et al. 2009; Wang et al. 2010; Sahoo et al. 2011), was used to estimate the kinetic parameters of 2C4NP biodegradation. The values of kinetic parameters for 2C4NP degradation obtained here were $\mu_{\max }=0.148 / \mathrm{h}, K_{\mathrm{s}}=0.022 \mathrm{mM}$, $K_{\mathrm{i}}=0.72 \mathrm{mM}\left(\mathrm{R}^{2}=0.955\right.$, standard deviation $\left.=0.067\right)$. The specific growth rate increased with increase of $2 \mathrm{C} 4 \mathrm{NP}$ when the substrate concentrations were less than 
Table 1 Effect of temperature, $\mathrm{pH}$, and glucose addition on 2C4NP degradation by strain CNP-8

\begin{tabular}{|c|c|c|c|c|}
\hline \multicolumn{2}{|l|}{ Abiotic factors } & \multirow{2}{*}{$\begin{array}{l}\mathbf{O D}_{600}^{\mathbf{d}} \\
0.105 \pm 0.007\end{array}$} & \multirow{2}{*}{$\begin{array}{l}\text { Time required for complete decolorization of 2C4NP (h) } \\
57 \pm 3.1\end{array}$} & \multirow{2}{*}{$\begin{array}{l}\text { Degradation rate }(\mu \mathrm{M} / \mathrm{h})^{\mathbf{e}} \\
5.3\end{array}$} \\
\hline Temperature $\left({ }^{\circ} \mathrm{C}\right)^{\mathrm{a}}$ & 20 & & & \\
\hline & 25 & $0.114 \pm 0.008$ & $28 \pm 1.9$ & 10.7 \\
\hline & 30 & $0.137 \pm 0.009$ & $21 \pm 2.2$ & 14.3 \\
\hline & 35 & $0.092 \pm 0.006$ & $31 \pm 2.6$ & 9.7 \\
\hline & 40 & $0.073 \pm 0.012$ & $62 \pm 4.5$ & 4.8 \\
\hline \multirow[t]{7}{*}{$\mathrm{pH}^{\mathrm{b}}$} & 4 & ND & ND & ND \\
\hline & 5 & $0.112 \pm 0.016$ & $32 \pm 2.6$ & 9.4 \\
\hline & 6 & $0.127 \pm 0.014$ & $22 \pm 1.4$ & 13.6 \\
\hline & 7 & $0.135 \pm 0.008$ & $20 \pm 2.5$ & 15.0 \\
\hline & 8 & $0.124 \pm 0.011$ & $23 \pm 1.8$ & 13.0 \\
\hline & 9 & $0.103 \pm 0.009$ & $38 \pm 2.7$ & 7.9 \\
\hline & 10 & $0.095 \pm 0.014$ & $54 \pm 3.8$ & 5.6 \\
\hline \multirow[t]{4}{*}{ Glucose addition $(\mathrm{g} / \mathrm{L})^{c}$} & - & $0.133 \pm 0.010$ & $21 \pm 1.8$ & 14.3 \\
\hline & 0.2 & $0.227 \pm 0.014$ & $12 \pm 2.4$ & 25.0 \\
\hline & 0.5 & $0.342 \pm 0.024$ & $16 \pm 1.6$ & 18.8 \\
\hline & 5 & $1.476 \pm 0.038$ & $49 \pm 5.4$ & 6.1 \\
\hline
\end{tabular}

MSM containing $0.3 \mathrm{mM}$ of 2 C4NP was inoculated by strain CNP-8 with initial $\mathrm{OD}_{600}$ about 0.05 and shaken at $180 \mathrm{rpm}$

pH of MSM was 7

${ }^{b}$ Culture temperature was $30^{\circ} \mathrm{C}$

c $\mathrm{pH}$ of MSM was 7 and culture temperature was $30^{\circ} \mathrm{C}$

d $\mathrm{OD}_{600}$ was determined at the time of complete decolorization of 2C4NP

e Rate of 2C4NP degradation $\left(\mu \mathrm{M} / \mathrm{h}^{-1}\right)=300 /$ time required for complete decolorization of 2C4NP

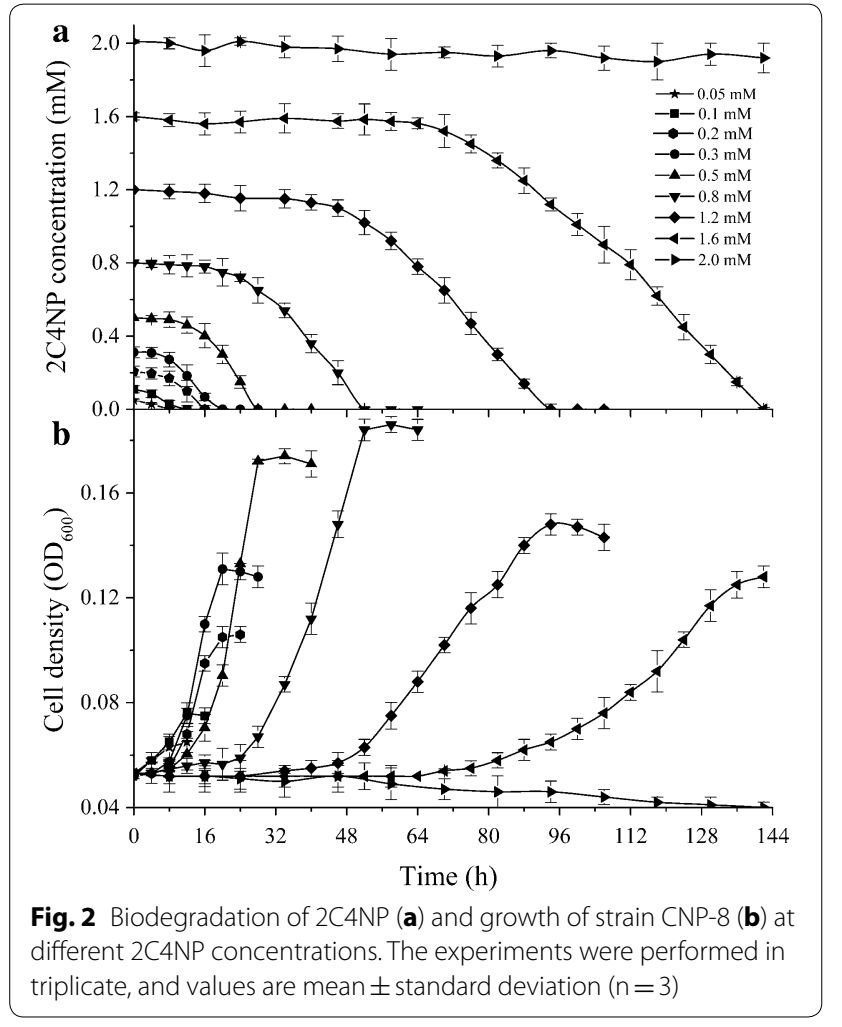

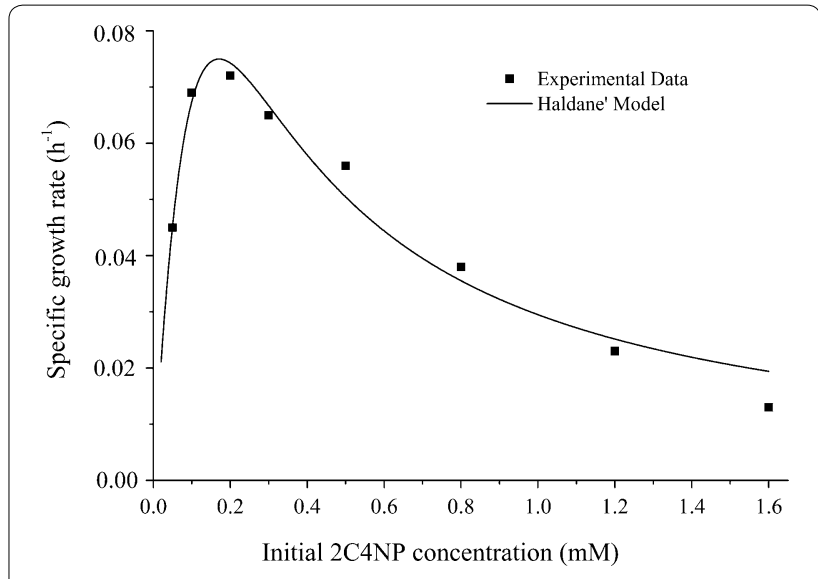

Fig. 3 Experimental and predicted (Haldane's model) specific growth rates of strain CNP-8

$0.16 \mathrm{mM}$ (Fig. 3). At concentrations beyond $0.16 \mathrm{mM}$, a considerable decline in the specific growth rate was observed by increasing the $2 \mathrm{C} 4 \mathrm{NP}$ concentration up to $1.6 \mathrm{mM}$. On the other hand, the biomass yield coefficient varied from 0.109 to $0.505 \mathrm{mg} / \mathrm{mg}$ when the initial 2C4NP concentration changed from 0.1 to $1.6 \mathrm{mM}$. The biomass yield coefficient changed slightly at low 2C4NP concentrations, and the highest yield coefficient 
$(0.505 \mathrm{mg} / \mathrm{mg})$ was obtained at a $2 \mathrm{C} 4 \mathrm{NP}$ concentration of $0.3 \mathrm{mM}$. Further increases in 2C4NP concentration led to significant decrease in the values of yield coefficient, apparently due to the inhibitory effect of 2C4NP against strain CNP-8.

\section{Identification of the metabolites of 2C4NP degradation}

The metabolites of 2C4NP degraded by strain CNP-8 were identified by HPLC and GC-MS analyses. No intermediate was detected when the sample was collected at 0 and $4 \mathrm{~h}$. Metabolite I with HPLC retention time of $5.18 \mathrm{~min}$ was captured in the sample of $12 \mathrm{~h}$ (Additional file 1: Figure S1). It was identified as $\mathrm{CHQ}$ by comparison of the retention time with that of the standard. In the sample of $16 \mathrm{~h}$, metabolite II with retention time of $8.07 \mathrm{~min}$ was also detected and it was identified as BT. Furthermore, GC-MS analysis of the acetylated products also detected two compounds, which were identified as acetylated CHQ $(m / z$ 228: molecular ion peak; $m / z$ 186: loss of one $-\mathrm{COCH}_{3} ; \mathrm{m} / z$ 144: loss of two $-\mathrm{COCH}_{3}$ ) and acetylated BT ( $m / z$ 252: molecular ion peak; $m / z 210$ : loss of one $-\mathrm{COCH}_{3} ; \mathrm{m} / z$ 168: loss of two $-\mathrm{COCH}_{3} ; \mathrm{m} / z$ 126: loss of three $-\mathrm{COCH}_{3}$ ), respectively (Additional file 1: Figure S2B and D). The identity of CHQ and BT was further confirmed by comparison with GC-MS analysis of the acetylated authentic compounds (Additional file 1: Figure S2A and C). On the basis of initial HPLC and GC-MS characterization, strain CNP-8 was proposed to degrade $2 \mathrm{C} 4 \mathrm{NP}$ with $\mathrm{BT}$ as a ring-cleavage compound.

\section{Whole cell biotransformation and cell extract assays}

Generally, the enzymes involved in the degradation of chlorinated nitroaromatic compounds were either inducible (Min et al. 2014, 2016) or constitutive (Gao et al. 2016). In this study, whole-cell biotransformation showed that the un-induced strain CNP-8 exhibited negligible activity for 2C4NP. However, the 2C4NP-induced cells degraded 2C4NP rapidly with a rate of approximately $0.271 \mathrm{mM} / \mathrm{h} \mathrm{OD}_{600} / \mathrm{cell}$, indicating that the enzymes involved in 2C4NP degradation in strain CNP-8 were inducible. Both $\mathrm{CHQ}$ and $\mathrm{BT}$ were detected during 2C4NP degradation. However, 2C4NP-induced cells of strain CNP-8 showed an evidently high rate of BT conversion (approximately $0.34 \mathrm{mM} / \mathrm{h} \quad \mathrm{OD}_{600} /$ cell) than the cells converting CHQ (approximately $0.012 \mathrm{mM} / \mathrm{h}$ $\mathrm{OD}_{600} /$ cell). Moreover, most previous 2C4NP-utilizers (Arora and Jain 2012; Min et al. 2014, 2016) were also able to degrade PNP and the catabolism of 2C4NP and PNP likely share the enzymes in these strains. However, the biotransformation assay showed that the 2C4NPinduced strain CNP-8 exhibited no activity for PNP (data not shown).
In the enzymatic assay, no activity of the cell extract against 2C4NP was observed when strain CNP-8 was grown in LB without 2C4NP induction. In contrast, the extract from the induced-cell transformed 2C4NP $\left(\lambda_{\max }=403 \mathrm{~nm}\right)$ rapidly, together with the consumption of NADPH $\left(\lambda_{\max }=340 \mathrm{~nm}\right.$ ) (Additional file 1: Figure S3A). Nitrite was also detected with the transformation of 2C4NP (data not shown). PNP transformation was not observed by the cell extract, in line with the result of the biotransformation. Degradation of BT by the cell extract also occurred, together with the formation of a new product with a maximum absorption at around $320 \mathrm{~nm}$ (Additional file 1: Figure S3B). This further proved that strain CNP-8 degraded 2C4NP via the BT pathway, apart from the identification of intermediate by HPLC and GC-MS assays.

\section{Chemotactic assays of strain CNP-8}

We also investigated the chemotactic behavior of strain CNP-8 toward various (chloro)nitrophenols by both qualitative and quantitative assays. Drop plate assay showed that strain CNP-8 exhibited positive chemotaxis toward 2C4NP, 2C5NP and MNP, but showed no chemotactic response toward PNP (Fig. 4a). In the capillary assay, strain CNP-8 exhibited chemotaxis toward 2C4NP with a maximum chemotaxis index of 37.5 when the concentration of 2C4NP was $0.5 \mathrm{mM}$. The values of the chemotaxis index increased gradually with increase of 2C4NP up to the optimal concentration (Fig. 4b), and then remained relatively stable for further increase in substrate concentration. When the concentration of 2C5NP and MNP was

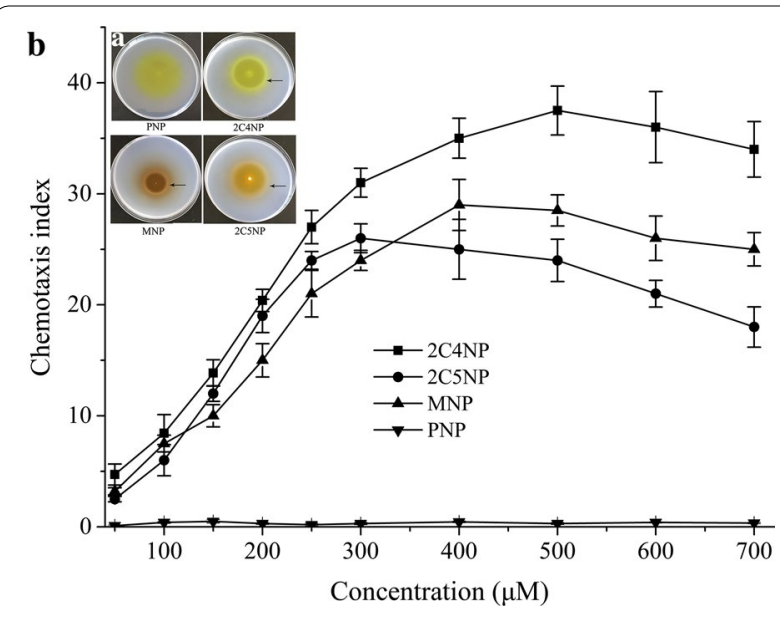

Fig. 4 Drop plate (a) and capillary assays (b) of chemotaxis of strain CNP-8 towards different (chloro)nitrophenols. The arrows in $\mathbf{a}$ are meant to indicate the chemotaxis rings. In the capillary assays, the average number of CFUs produced from the control capillaries was $3.17 \times 10^{4}$. The capillary assays were performed in triplicate, and values are mean \pm standard deviation $(n=3)$ 
0.3 and $0.4 \mathrm{mM}$, respectively, strain CNP- 8 exhibited the strongest chemotactic response toward these two chemoattractants, with chemotaxis index of 25.8 and 29.2, respectively. In contrast to these three compounds, strain CNP-8 exhibited no chemotactic response toward PNP at any concentration (Fig. 4b), in line with the result of drop plate assay.

\section{Bioremediation of 2C4NP-contaminated soil by strain CNP-8}

The capability of strain CNP-8 to remediate 2C4NPcontaminated soil was investigated by setting up 6 different microcosm using both nonsterile and sterile soils. Degradation of 2C4NP occurred rapidly in inoculated treatments (T3, T4, T5 and T6) than in the un-inoculated treatments (T1 and T2) (Fig. 5). In the inoculated non-sterile treatment $\mathrm{T} 3$ and inoculated sterile treatment T5, 2C4NP was completely removed on day 12 and 10 , respectively. However, there was still $2 \mathrm{C} 4 \mathrm{NP}$ in the un-inoculated non-sterile soil (T1) and un-inoculated sterile soil (T2) after 16 days of incubation, with $82 \%(80.3 \pm 4.6 \mu \mathrm{g} / \mathrm{g} \mathrm{dw})$ and $91 \%(87.5 \pm 5.2 \mu \mathrm{g} / \mathrm{g} \mathrm{dw})$ of the initial $2 \mathrm{C} 4 \mathrm{NP}$ remained, respectively. It is obvious that the inoculated strain CNP-8 played crucial role in removing $2 \mathrm{C} 4 \mathrm{NP}$ in the contaminated soil, whereas the indigenous microorganisms seemed to have no ability to degrade $2 \mathrm{C} 4 \mathrm{NP}$. The $2 \mathrm{C} 4 \mathrm{NP}$ degradation rate in inoculated non-sterile soil (T3) is lower than that in inoculated sterile soil (T5). When un-induced cells of strain CNP-8 were inoculated in non-sterile soil (T3) and sterile soil (T5), the removal of $2 \mathrm{C} 4 \mathrm{NP}$ has a lag phase of about 3 days (Fig. 5). However, degradation of 2C4NP in the inoculated induced groups ( $\mathrm{T} 4$ and $\mathrm{T} 6$ ) had no delay period. So, it is our view that the pre-induced strain CNP-8 is more suitable for the bioremediation of 2C4NP-contaminated soil.

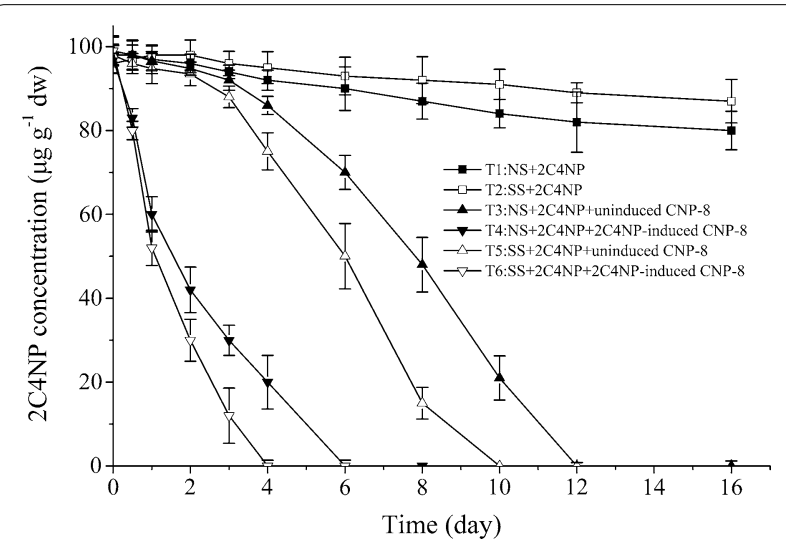

Fig. 5 Biodegradation of 2C4NP by strain CNP-8 in soil microcosms. The experiments were performed in triplicate, and values are mean \pm standard deviation $(n=3)$. NS native soil, SS sterilized soil

\section{Discussion}

Several pure bacterial cultures have been isolated based on their ability to degrade 2C4NP (Ghosh et al. 2010; Arora and Jain 2011; Pandey et al. 2011; Arora and Jain 2012; Tiwari et al. 2017), but strain CNP-8 reported in present study is able to tolerate and degrade higher concentrations of 2C4NP than any other 2C4NP-utilizers. Our 2C4NP-degrading isolate can utilize 2C4NP up to concentration of $1.6 \mathrm{mM}$, while 2C4NP more than $0.5 \mathrm{mM}$ has been reported to completely inhibit the growth of previously reported 2C4NP-utilizers including Burkholderia sp. RKJ800 (Arora and Jain 2012) and Cupriavidus strain a3 (Tiwari et al. 2017). Moreover, strain CNP-8 can adapt to a wide range of $\mathrm{pH}$ from 5 to 10 , whereas strain a3 was reported to be unable to degrade 2C4NP at pH lower than 6 or higher than 9 (Tiwari et al. 2017). On the other hand, strain CNP-8 is also capable to utilize 2C5NP, which is the isomer of 2C4NP and usually coexist with 2C4NP in the industrial wastewater. However, there are no documented cases of 2C5NP degradation by other 2C4NP-degrading bacteria. From a practical point of view, these combined advantages of strain CNP-8 indicated that it could be a promising candidate for bioremediation of chloronitrophenols-contaminated environment.

The kinetic parameters of microbial pollutant degradation can enhance our understanding of the capability of degrading microorganisms and help us to compare the degradation efficiency among different isolates (Shen et al. 2009). The utilization of 2C4NP by strain CNP-8 followed the typical Haldane substrate inhibition model, in line with the reports of microbial degradation of numerous toxicants including phenol (Wang et al. 2010; Zhai et al. 2012; Basak et al. 2014), p-cresol (Singh et al. 2008), chlorobenzene (Zhang et al. 2011) and 4-chlorophenol (Sahoo et al. 2011). The value of biomass yield coefficient decreased at high 2C4NP concentration, likely due to that more energy was required to overcome the substrate inhibitory effect when the initial 2C4NP concentration was too high. Moreover, the accumulation of nitrite is likely another possible factor resulting in the decrease of the biomass yield coefficient when the concentration of $2 \mathrm{C} 4 \mathrm{NP}$ more than $0.3 \mathrm{mM}$. Although there is a substrate inhibition, the evidently higher value of $K_{\mathrm{s}}$ (substrate affinity) than $K_{\mathrm{i}}$ (substrate inhibition) during 2C4NP degradation indicated that strain CNP-8 could efficiently degrade 2C4NP from the kinetic perspective. Moreover, strain CNP-8 had higher 2C4NP affinity and degradation efficiency than another 2C4NP-utilizer Cupriavidus strain a3 (Tiwari et al. 2017) by comparing the kinetic parameters of 2C4NP degradation.

Microbial chemotaxis was proposed to be helpful for bioremediation because previous studies have proved 
that chemotaxis can enhance the bioavailability of pollutants and/or promoted microbial consortia of various microorganisms with complementary degradation capabilities (Gordillo et al. 2007; Pandey et al. 2012; Arora and Bae 2014). In current study, it is clear that strain CNP-8 exhibited chemotaxis toward 2C4NP, 2C5NP and MNP, as evidenced by the formation of concentric chemotaxis rings and the determination of the chemotaxis indexes. Several 2C4NP-utilizers has been isolated (Ghosh et al. 2010; Arora and Jain 2011; Pandey et al. 2011; Arora and Jain 2012; Tiwari et al. 2017), but only Burkholderia sp. strain SJ98 exhibited chemotaxis toward 2C4NP, and its chemotaxis toward 2C5NP and MNP was not reported (Pandey et al. 2012). Pseudomonas sp. JHN showed chemotaxis toward 4C2NP (Arora and Bae 2014) and 4-chloro-3-nitrophenol (Arora et al. 2014b), two isomers of 2C4NP; however, it showed no chemotactic behavior toward 2C4NP and 2C5NP. To date, both metabolismdependent chemotaxis and metabolism-independent chemotaxis of aromatic compounds have been studied in bacteria (Zhang et al. 2008; Arora and Bae 2014). The chemotaxis of strain CNP-8 towards (chloro)nitrophenols is likely a typical metabolism-dependent chemotaxis, as evidenced by the fact that strain CNP-8 only exhibited chemotaxis toward the compounds which it can utilize.

The detection of $\mathrm{CHQ}$ indicated that the degradation of 2C4NP by strain CNP-8 was initiated by a 2C4NP 4-monooxygenase. It is well known that a monooxygenase attack on an aromatic ring at a position substituted by an electron-withdrawing group forms a quinone compound (Entsch et al. 1980; Haigler et al. 1996; Xun and Webster 2004; Perry and Zylstra 2007), while an attack at an unoccupied position forms a quinol compound (Whited and Gibson 1991; Tao et al. 2004). Therefore, the first intermediate of catabolism of $2 \mathrm{C} 4 \mathrm{NP}$ was proposed as chloro-1,4-benzoquinone (CBQ). The identification of BT suggested that CBQ was subsequently dechlorinated to BT likely via 2-hydroxy-1,4-benzoquinone (Fig. 6A), similar with the catabolism of 2,4,6-trichlorophenol in Cupriavidus necator JMP134 (Xun and Webster 2004). Both CBQ and 2-hydroxy-1,4-benzoquinone were not detected during 2C4NP degradation is likely due to that they were easily reduced to $\mathrm{CHQ}$ and BT, respectively by nonenzymatic transformation, in line with the hypotheses of nonenzymatic reduction of other quinone compounds (Xun and Webster 2004; Perry and Zylstra 2007; Zhang et al. 2009; Yamamoto et al. 2011; Min et al. 2014; 2016). This speculation was further justified by the detection of CHQ during 2C4NP degradation. CHQ may not be a true intermediate because the 2C4NP-induced cells of strain CNP-8 hardly transformed CHQ.

The 2C4NP catabolic pathway identified in strain CNP-8 is different from those reported in other 2C4NP utilizers. Pandey et al. have reported that Burkholderia sp. strain SJ98 initiated 2C4NP degradation with formation of para-nitrophenol, which was then transformed to BT via 4-nitrocatechol (Fig. 6C) (Pandey et al. 2011); however, subsequent genetic and biochemical identification suggested CHQ pathway is likely the actual pathway of 2C4NP catabolism in this strain (Fig. 6B) (Min et al. 2014). In this study, BT was identified as the ring cleavage substrate during 2 C4NP degradation by strain CNP8. This clearly reveals that the removal of chloro group occurs before ring cleavage during 2C4NP catabolism in strain CNP-8, whereas the chloro group was removed after ring cleavage in strain SJ98. Although the removal of chloro group also occurs before ring cleavage during 2C4NP degradation by Burkholderia sp. RKJ800 (Fig. 6D), HQ rather than BT was identified as the ring cleavage substrate (Arora and Jain 2012). Rhodococcus imtechensis RKJ 300, a Gram-positive 2C4NP-utilizer, was reported to degrade $2 \mathrm{C} 4 \mathrm{NP}$ with $\mathrm{BT}$ as a ring cleavage substrate, which was then transformed to maleylacetate $\left(\lambda_{\max }=243 \mathrm{~nm}\right.$ ) by BT dioxygenase (Min et al. 2016). In present study, although the ring fission product of BT was not identified, enzymatic assay clearly showed that the product of BT had a $\lambda_{\max }$ of $320 \mathrm{~nm}$ (Additional file 1: Figure S3B), apparently different from the spectral property of maleylacetate. To our knowledge, this is the first report of $2 \mathrm{C} 4 \mathrm{NP}$ degradation via the $\mathrm{BT}$ pathway in a Gram-negative 2C4NP utilizer, and this finding could enhance our understanding of the diversity of metabolic pathways of microbial 2C4NP degradation.

More interestingly, most 2C4NP-utilizers including Burkholderia sp. strain SJ98 (Min et al. 2014), Burkholderia sp. strain RKJ800 (Arora and Jain 2012) and Rhodococcus imtechensis RKJ 300 (Ghosh et al. 2010) were also able to grow on PNP. In particular, both the singlecomponent 2C4NP monooxygenase (PnpA) from the Gram-negative strain SJ98 (Min et al. 2014) and the twocomponent 2C4NP monooxygenase (PnpA1A2) from the Gram-positive strain RKJ 300 (Min et al. 2016) were reported to be able to catalyze the monooxygenation of 2C4NP and PNP. In contrast, enzymatic assay in present study clearly revealed that the monooxygenase involved in 2C4NP catabolism in strain CNP-8 was unable to catalyze the transformation of PNP, indicating its special substrate spectrum as compared to other reported 2C4NP 
<smiles>CC1=CC(=O)C(Cl)=CC1=O</smiles>

Chloro-1,4-benzoquinone 2-Hydroxy-1,4-benzoquinone Hydroxyquinol<smiles>O=[N+]([O-])c1ccc(O)c(Cl)c1</smiles>

2-Chloro-4-nitrophenol

(2C4NP)

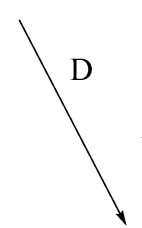

Chloro-1,4-benzoquinone (CBQ)<smiles>O=C1C=CC(=O)C(Cl)=C1</smiles><smiles>Oc1ccc(O)c(Cl)c1</smiles>

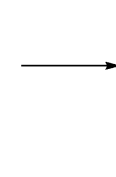

Chlorohydroquinone

(CHQ)<smiles>O=[N+]([O-])c1ccc(O)cc1</smiles>
para-Nitrophenol<smiles>O=C1C=CC(=O)C(Cl)=C1</smiles>

Chloro-1,4-benzoquinone (CBQ)<smiles>Oc1ccc(O)c(Cl)c1</smiles>

Chlorohydroquinone

(CHQ)
(BT)<smiles>O=C(O)/C=C(/Cl)C=C(O)Cl</smiles>

2-Chloro-4-hydroxymuconic semialdehyde<smiles>Oc1ccc(O)c(O)c1</smiles>

Hydroxyquinol

(BT)<smiles>Oc1ccc(O)cc1</smiles>

Hydroquinone

(HQ)

Fig. 6 Proposed pathways of 2C4NP degradation by 2C4NP utilizers. (A) Cupriavidus sp. strain CNP-8 (this pathway was also seen with Rhodococcus imtechensis strain RKJ300, reported previously); (B) Burkholderia sp. strain SJ98 [reported by Min et al. (2014)]; (C) Burkholderia sp. strain SJ98 [reported by Pandey et al. (2011)]; (D) Burkholderia sp. strain RKJ800. The unidentified intermediates are in brackets. The structures of ring cleavage compounds are indicated in boldface

monooxygenations. Now, the purification and characterization of enzymes involved in 2C4NP catabolism in strain CNP-8 is in progress, and the genetic characterization of strain CNP-8 will be the subject of further work.

\section{Additional file}

Additional file 1: Table S1. Degradation capability of strain CNP-8 for various nitrophenols. Figure $\mathbf{S 1}$. HPLC identification of the intermediates of 2C4NP degradation by strain CNP-8. Figure S2. Mass spectra of the acetylated derivatives of the intermediates during 2C4NP degradation by strain CNP-8. (A) Acetylated derivative of authentic CHQ. (B) Acetylated metabolite I. (C) Acetylated derivative of authentic BT. (D) Acetylated metabolite II. Figure S3. Transformation of $2 \mathrm{C} 4 \mathrm{NP}$ (A) and BT (B) by the cell extract of 2C4NP-induced strain CNP-8.

\section{Abbreviations}

2C4NP: 2-chloro-4-nitrophenol; 2C5NP: 2-chloro-5-nitrophenol; BT: 1,2,4-benzenetriol (hydroxyquinol); CHQ: chlorohydroquinone; CNPs: chloronitrophenols; $\mathrm{HQ}$ : hydroquinone; $K_{i}$ : substrate inhibition constant; $K_{s}$ : half saturation constant; PNP: para-nitrophenol; $\mu_{\max }$ : maximum specific growth rate.

\section{Authors' contributions}

$J M$ and $\mathrm{XH}$ conceived and designed the experiments; JM, JW and WC performed the experiments; JM analyzed the data; JM and XH wrote the paper. All authors read and approved the final manuscript.

\section{Author details}

${ }^{1}$ Key Laboratory of Coastal Biology and Bioresource Utilization, Yantai Institute of Coastal Zone Research, Chinese Academy of Sciences, Yantai 264003, China.

${ }^{2}$ Key Laboratory of Agricultural and Environmental Microbiology, Wuhan Institute of Virology, Chinese Academy of Sciences, Wuhan 430071, China.

\section{Acknowledgements}

Not applicable. 


\section{Competing interests}

The authors declare that they have no competing interests.

\section{Availability of data and materials}

Not applicable.

\section{Consent for publication}

Not applicable.

\section{Ethical approval and consent to participate}

This article does not contain any studies with human participants or animals performed by authors.

\section{Funding}

This work was supported by the National Natural Science Foundation of China (31600085), the Foreword Key Priority Research Program of Chinese Academy of Sciences (QYZDB-SSW-DQC013), the National Key Research Program of China (2016YFC1402300), the State Key Laboratory of Microbial Metabolism, Shanghai JiaoTong University (MMLKF15-04), and the Yantai Science and Technology Project (2017YT06000325).

\section{Publisher's Note}

Springer Nature remains neutral with regard to jurisdictional claims in published maps and institutional affiliations.

Received: 28 February 2018 Accepted: 12 March 2018

Published online: 20 March 2018

\section{References}

Arora PK, Bae H (2014) Biotransformation and chemotaxis of 4-chloro-2-nitrophenol by Pseudomonas sp. JHN. Microb Cell Fact 13:110. https://doi. org/10.1186/s12934-014-0110-7

Arora PK, Jain RK (2011) Pathway for degradation of 2-chloro-4-nitrophenol in Arthrobacter sp. SJCon. Curr Microbiol 63:568-573. https://doi. org/10.1007/s00284-011-0022-2

Arora PK, Jain RK (2012) Metabolism of 2-chloro-4-nitrophenol in a Gram negative bacterium, Burkholderia sp. RKJ 800. PLoS ONE 7:38676. https://doi. org/10.1371/journal.pone.0038676

Arora PK, Sharma A, Mehta R, Shenoy BD, Srivastava A, Singh VP (2012a) Metabolism of 4-chloro-2-nitrophenol in a Gram-positive bacterium Exiguobacterium sp. PMA. Microb Cell Fact 11:150. https://doi. org/10.1186/1475-2859-11-150

Arora PK, Sasikala C, Ramana Ch V (2012b) Degradation of chlorinated nitroaromatic compounds. Appl Microbiol Biotechnol 93:2265-2277. https://doi. org/10.1007/s00253-012-3927-1

Arora PK, Srivastava A, Singh VP (2014a) Bacterial degradation of nitrophenols and their derivatives. J Hazard Mater 266:42-59. https://doi.org/10.1016/j. jhazmat.2013.12.011

Arora PK, Srivastava A, Singh VP (2014b) Degradation of 4-chloro-3-nitrophenol via a novel intermediate, 4-chlororesorcinol by Pseudomonas sp. JHN. Sci Rep 4:4475. https://doi.org/10.1038/srep04475

Banerjee A, Ghoshal AK (2011) Phenol degradation performance by isolated Bacillus cereus immobilized in alginate. Int Biodeterior Biodegrad 65:1052-1060. https://doi.org/10.1016/j.ibiod.2011.04.011

Basak B, Bhunia B, Dutta S, Chakraborty S, Dey A (2014) Kinetics of phenol biodegradation at high concentration by a metabolically versatile isolated yeast Candida tropicalis PHB5. Environ Sci Pollut R 21:1444-1454. https:// doi.org/10.1007/s11356-013-2040-Z

Chi XQ, Zhang JJ, Zhao S, Zhou NY (2013) Bioaugmentation with a consortium of bacterial nitrophenol-degraders for remediation of soil contaminated with three nitrophenol isomers. Environ Pollut 172:33-41. https://doi. org/10.1016/j.envpol.2012.08.002

Entsch B, Husain M, Ballou DP, Massey V, Walsh C (1980) Oxygen reactivity of p-hydroxybenzoate hydroxylase containing 1-deaza-FAD. J Biol Chem 255:1420-1429

Gao YZ, Liu H, Chao HJ, Zhou NY (2016) Constitutive expression of a Nag-like dioxygenase gene through an internal promoter in the 2-chloronitrobenzene catabolism gene cluster of Pseudomonas stutzeri ZWLR2-1. Appl Environ Microbiol 82:3461-3470. https://doi.org/10.1128/ Aem.00197-16

Ghosh A, Khurana M, Chauhan A, Takeo M, Chakraborti AK, Jain RK (2010) Degradation of 4-nitrophenol, 2-chloro-4-nitrophenol, and 2,4-dinitrophenol by Rhodococcus imtechensis strain RKJ300. Environ Sci Technol 44:1069-1077. https://doi.org/10.1021/es9034123

Gordillo F, Chavez FP, Jerez CA (2007) Motility and chemotaxis of Pseudomonas sp. B4 towards polychlorobiphenyls and chlorobenzoates. FEMS Microbiol Ecol 60:322-328. https://doi.org/10.1111/j.1574-6941.2007.00293.x

Haigler BE, Suen WC, Spain JC (1996) Purification and sequence analysis of 4-methyl-5-nitrocatechol oxygenase from Burkholderia sp. strain DNT. J Bacteriol 178:6019-6024

Lessner DJ, Johnson GR, Parales RE, Spain JC, Gibson DT (2002) Molecular characterization and substrate specificity of nitrobenzene dioxygenase from Comamonas sp. strain JS765. Appl Environ Microbiol 68:634-641. https:// doi.org/10.1128/Aem.68.2.634-641.2002

Liu PP, Zhang JJ, Zhou NY (2010) Characterization and mutagenesis of a twocomponent monooxygenase involved in para-nitrophenol degradation by an Arthrobacter strain. Int Biodeterior Biodegrad 64:293-299. https:// doi.org/10.1016/j.ibiod.2010.03.001

Min J, Zhang JJ, Zhou NY (2014) The gene cluster for para-nitrophenol catabolism is responsible for 2-chloro-4-nitrophenol degradation in Burkholderia sp. strain SJ98. Appl Environ Microbiol 80:6212-6222. https:// doi.org/10.1128/AEM.02093-14

Min J, Zhang JJ, Zhou NY (2016) A two-component para-nitrophenol monooxygenase initiates a novel 2-chloro-4-nitrophenol catabolism pathway in Rhodococcus imtechensis RKJ300. Appl Environ Microbiol 82:714-723. https://doi.org/10.1128/Aem.03042-15

Min J, Wang B, Hu X (2017a) Effect of inoculation of Burkholderia sp. strain SJ98 on bacterial community dynamics and para-nitrophenol, 3-methyl-4-nitrophenol, and 2-chloro-4-nitrophenol degradation in soil. Sci Rep 7:5983. https://doi.org/10.1038/s41598-017-06436-0

Min J, Chen W, Wang J, Hu X (2017b) Genetic and biochemical characterization of 2-chloro-5-nitrophenol degradation in a newly isolated bacterium, Cupriavidus sp. strain CNP-8. Front Microbiol 8:1778. https://doi. org/10.3389/fmicb.2017.01778

Niu GL, Zhang JJ, Zhao S, Liu H, Boon N, Zhou NY (2009) Bioaugmentation of a 4-chloronitrobenzene contaminated soil with Pseudomonas putida ZWL73. Environ Pollut 157:763-771. https://doi.org/10.1016/j. envpol.2008.11.024

Pandey J, Heipieper HJ, Chauhan A, Arora PK, Prakash D, Takeo M, Jain RK (2011) Reductive dehalogenation mediated initiation of aerobic degradation of 2-chloro-4-nitrophenol (2 (4NP) by Burkholderia sp. strain SJ98. Appl Microbiol Biotechnol 92:597-607. https://doi.org/10.1007/ s00253-011-3254-y

Pandey J, Sharma NK, Khan F, Ghosh A, Oakeshott JG, Jain RK, Pandey G (2012) Chemotaxis of Burkholderia sp. strain SJ98 towards chloronitroaromatic compounds that it can metabolise. BMC Microbiol 12:19. https://doi. org/10.1186/1471-2180-12-19

Perry LL, Zylstra GJ (2007) Cloning of a gene cluster involved in the catabolism of $p$-nitrophenol by Arthrobacter sp. strain JS443 and characterization of the $p$-nitrophenol monooxygenase. J Bacteriol 189:7563-7572. https:// doi.org/10.1128/JB.01849-06

Priya MH, Madras G (2006) Kinetics of photocatalytic degradation of phenols with multiple substituent groups. J Photoch Photobio A 179:256-262. https://doi.org/10.1016/j.jphotochem.2005.08.022

Sahoo NK, Pakshirajan K, Ghosh PK, Ghosh A (2011) Biodegradation of 4-chlorophenol by Arthrobacter chlorophenolicus A6: effect of culture conditions and degradation kinetics. Biodegradation 22:275-286. https:// doi.org/10.1007/s10532-010-9396-2

Shen JY, He R, Wang LJ, Zhang JF, Zuo Y, Li YC, Sun XY, Li JS, Han WQ (2009) Biodegradation kinetics of picric acid by Rhodococcus sp. NJUST16 in batch reactors. J Hazard Mater 167:193-198. https://doi.org/10.1016/j. jhazmat.2008.12.100

Singh RK, Kumar S, Kumar S, Kumar A (2008) Biodegradation kinetic studies for the removal of $p$-cresol from wastewater using Gliomastix indicus MTCC 3869. Biochem Eng J 40:293-303. https://doi.org/10.1016/j. bej.2007.12.015

Tao Y, Fishman A, Bentley WE, Wood TK (2004) Oxidation of benzene to phenol, catechol, and 1,2,3-trihydroxybenzene by toluene 4-monooxygenase 
of Pseudomonas mendocina KR1 and toluene 3-monooxygenase of Ralstonia pickettii PKO1. Appl Environ Microbiol 70:3814-3820. https://doi. org/10.1128/AEM.70.7.3814-3820.2004

Tiwari J, Naoghare P, Sivanesan S, Bafana A (2017) Biodegradation and detoxification of chloronitroaromatic pollutant by Cupriavidus. Bioresour Technol 223:184-191. https://doi.org/10.1016/j.biortech.2016.10.043

Verma A, Dixit D, Toor A, Srivastava J (2015) Heterogeneous photocatalytic degradation of 2-chloro-4-nitrophenol using slurry and fixed bed reactor. Environ Prog Sustain 34:380-386. https://doi.org/10.1002/ep.11997

Wang LM, Li Y, Yu P, Xie ZX, Luo YB, Lin YW (2010) Biodegradation of phenol at high concentration by a novel fungal strain Paecilomyces variotii JH6. J Hazard Mater 183:366-371. https://doi.org/10.1016/j.jhazmat.2010.07.033

Wang L, Chi XQ, Zhang JJ, Sun DL, Zhou NY (2014) Bioaugmentation of a methyl parathion contaminated soil with Pseudomonas sp. strain WBC-3. Int Biodeterior Biodegrad 87:1 16-121. https://doi.org/10.1016/j. ibiod.2013.11.008

Whited GM, Gibson DT (1991) Toluene-4-monooxygenase, a three-component enzyme system that catalyzes the oxidation of toluene to $p$-cresol in Pseudomonas mendocina KR1. J Bacteriol 173:3010-3016

Xu Y, Zhou NY (2017) Microbial remediation of aromatics-contaminated soil. Front Environ Sci Eng. https://doi.org/10.1007/s11783-017-0894-x
Xun L, Webster CM (2004) A monooxygenase catalyzes sequential dechlorinations of 2,4,6-trichlorophenol by oxidative and hydrolytic reactions. J Biol Chem 279:6696-6700. https://doi.org/10.1074/jbc.M312072200

Yamamoto K, Nishimura M, Kato D, Takeo M, Negoro S (2011) Identification and characterization of another 4-nitrophenol degradation gene cluster, nps, in Rhodococcus sp. strain PN1. J Biosci Bioeng 111:687-694. https:// doi.org/10.1016/j.jbiosc.2011.01.016

Zhai ZJ, Wang HL, Yan SB, Yao JM (2012) Biodegradation of phenol at high concentration by a novel bacterium: Gulosibacter sp. YZ4. J Chem Technol Biot 87:105-111. https://doi.org/10.1002/jctb.2689

Zhang JJ, Xin YY, Liu H, Wang SJ, Zhou NY (2008) Metabolism-independent chemotaxis of Pseudomonas sp. strain WBC-3 toward aromatic compounds. J Environ Sci 20:1238-1242

Zhang JJ, Liu H, Xiao Y, Zhang XE, Zhou NY (2009) Identification and characterization of catabolic para-nitrophenol 4-monooxygenase and parabenzoquinone reductase from Pseudomonas sp. strain WBC-3. J Bacteriol 191:2703-2710. https://doi.org/10.1128/JB.01566-08

Zhang LL, Leng SQ, Zhu RY, Chen JM (2011) Degradation of chlorobenzene by strain Ralstonia pickettii $\mathrm{L} 2$ isolated from a biotrickling filter treating a chlorobenzene-contaminated gas stream. Appl Microbiol Biotechnol 91:407-415. https://doi.org/10.1007/s00253-011-3255-x

\section{Submit your manuscript to a SpringerOpen ${ }^{\circ}$ journal and benefit from:}

- Convenient online submission

- Rigorous peer review

- Open access: articles freely available online

- High visibility within the field

- Retaining the copyright to your article

Submit your next manuscript at $\boldsymbol{\nabla}$ springeropen.com 